\title{
Accessing Information
}

\section{Abstract}

After completing this learning unit, you will be able to:

- Define the need for information;

- Identify the stages of a research strategy;

- Build personalised research objectives according to information requirements; and

- Analyse the effect of different methods for searching for information.

\section{Keywords}

Need of information $\cdot$ Searching strategies $\cdot$ Boolean search

\section{Summary}

Accessing information is based upon two elements:

- Define and outline the need of information; and

- Location/Information retrieval.

\subsection{Defining the Need of Information}

Users' information needs change as a consequence of electronic documents, whose content is available for all users. These information needs are only expectations of library users, depending on the librarians' needs to re-orientate their collections and services, while the user feedback is considered as particular factor in measuring the usefulness and efficiency of every library. In order to document, they need to define their requirements, to formulate key-questions, and, of course, to know how to locate, assess and use information from several electronic sources. 


\subsubsection{Expressing and Defining the Need of Information}

- Research initiation: you have to create a report, a theme, an essay, or a project;

- Writing techniques; and

- Research initiation methods.

\subsection{Research Question}

Definition of research subject matter will involve the following stages:

- Formulating a preliminary question, writing a few lines to specify what you aim to research and expectations of research results; and

- Starting with a theme sketch.

A research question should observe the following conditions:

- It is short and accurate;

- Clearly describes the main research questions;

- Must additionally offer the possibility of motivating research;

- It has to be realistic and lead to a conclusion; and

- The research question is not specific in the beginning; it becomes gradually clearwhile conducting the research.

Creating a preliminary research question should answer the following questions:

- Which aspect of the subject do you wish to investigate?

- What theoretical perspective are you going to use?

- What methods did others use?

\subsection{Research Strategies}

We propose refining research terms using the following methods (Fig. 4.1):

\subsection{Keywords}

Keywords are words that define the thematic content of a document. A keyword is a word or a phrase, significant for the research topic that will allow reference retrieval in order to retrieve information.

Finding and combining keywords. 
Fig. 4.1 Search strategies

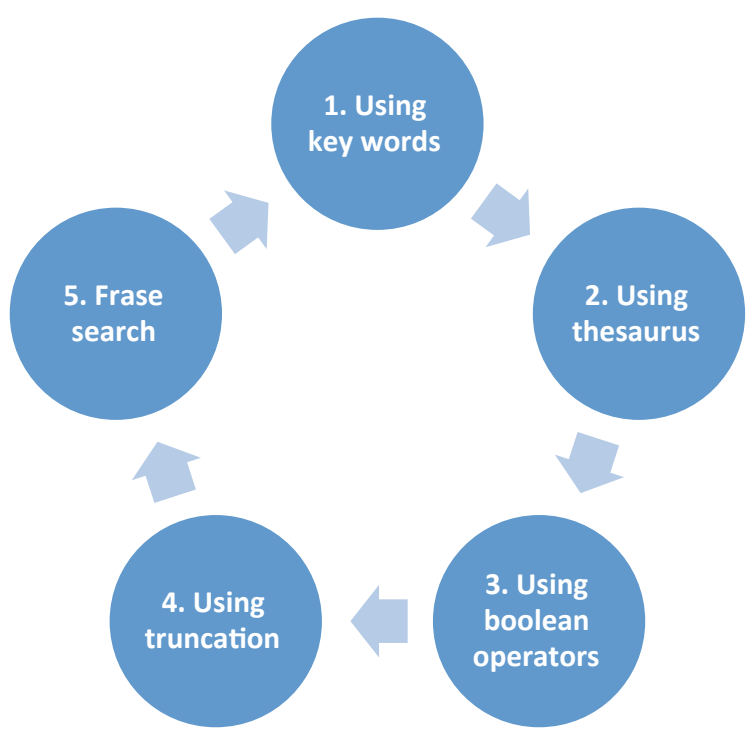

After an overview of the research field, a preliminary research question is formulated and an outline or scheme is designed, then we look for the required information to support and develop the proposed theme. A detailed search is started. An indicative research offers keywords related to the research question and outline. Keywords are used for searching.

Keywords may have various meanings in different academic subjects. We need to find the suitable word for the researched subject matter.

A keyword maybe indexed in a one database but not indexed in another. The use of a keyword is different according to the research field:

- General terms are used for libraries;

- Specific terms are used for academic databases; and

- Common terms for news databases.

Other factors to be taken into account for defining keywords are:

- Find out if the databases have a subjects' index or a thesaurus (hierarchical index of topics, for example PubMed language MeSH)

- What is the language used in the research?

- If it is English, we need to consider that certain words are different in UK English with respect to American English

- Do the keywords have synonyms?

A list of words is developed using the following Table 4.1. 
Table 4.1 Keywords

\begin{tabular}{|l|l|l|l|l|}
\hline Keywords in English & English synonyms & $\begin{array}{l}\text { Keywords in other } \\
\text { languages }\end{array}$ & $\begin{array}{l}\text { Synonyms in other } \\
\text { languages }\end{array}$ \\
\hline & & & \\
\hline
\end{tabular}

A search keyword uses free text to identify all the records including the word or words introduced in the search environment. The results may come from any aspect of the recorded data, meaning elements of bibliographic description, such as: title, abstract, and subject within the libraries' catalogues, databases and websites.

Websites are more easily retrieved with keywords from common language, while databases use a controlled vocabulary, a list of terms in a form used for the document's processing.

\subsection{Using a Thesaurus}

A thesaurus is a predefined set of terms used to describe the content of an article. A search based on a controlled vocabulary will provide optimal results if we look in the databases using that specific vocabulary.

Example: Controlled vocabulary Medical Subject Headings (Mesh) is the vocabulary used for indexing medical subjects in the World Health Organization (WHO) database, PubMed, which is a free to access medical database available on the Internet.

The use of predefined indexing terms will allow a more accurate search based on the structured language of the database. Also, for publishing in certain journals, the authors are directed to check the keywords in the MeSH controlled vocabulary and to use then in the form adopted there so that the article's retrieval systems have maximum effect (Fig. 4.2).

Another very often-used thesaurus, in Romanian libraries also, is EuroVocmultilingual thesaurus of the European Union, available in many language interface, http://eurovoc.europa.eu/ (Fig. 4.3).

After selecting the domain and language, then the DOWNLOAD button is clicked and we retrieve an electronic document containing a list of general and specific terms used in this thesaurus (Fig. 4.4).

We can also search in ProQuest, an Ann Arbor, Michigan-based global information-content and technology company, founded in 1938 as University Microfilms by Eugene B. Power. (Fig.) ProQuest provides solutions, applications, and products for libraries. ProQuest provides the British Nursing Indexing Thesaurus (Figs. 4.5, 4.6 and 4.7) (Proquest.com 2018). 


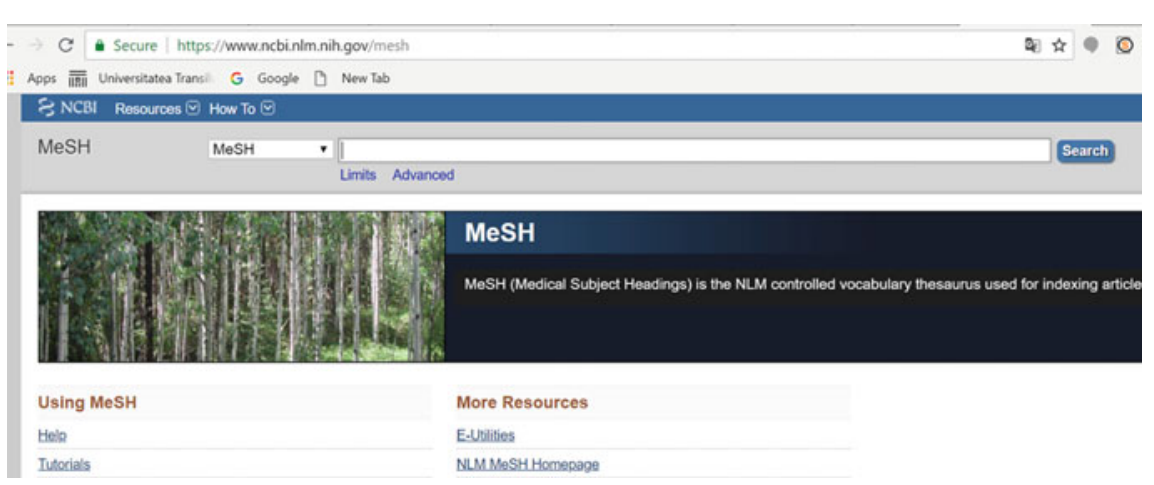

Fig. 4.2 System for checking and identification of keywords used in controlled vocabulary $\mathrm{MeSH}$

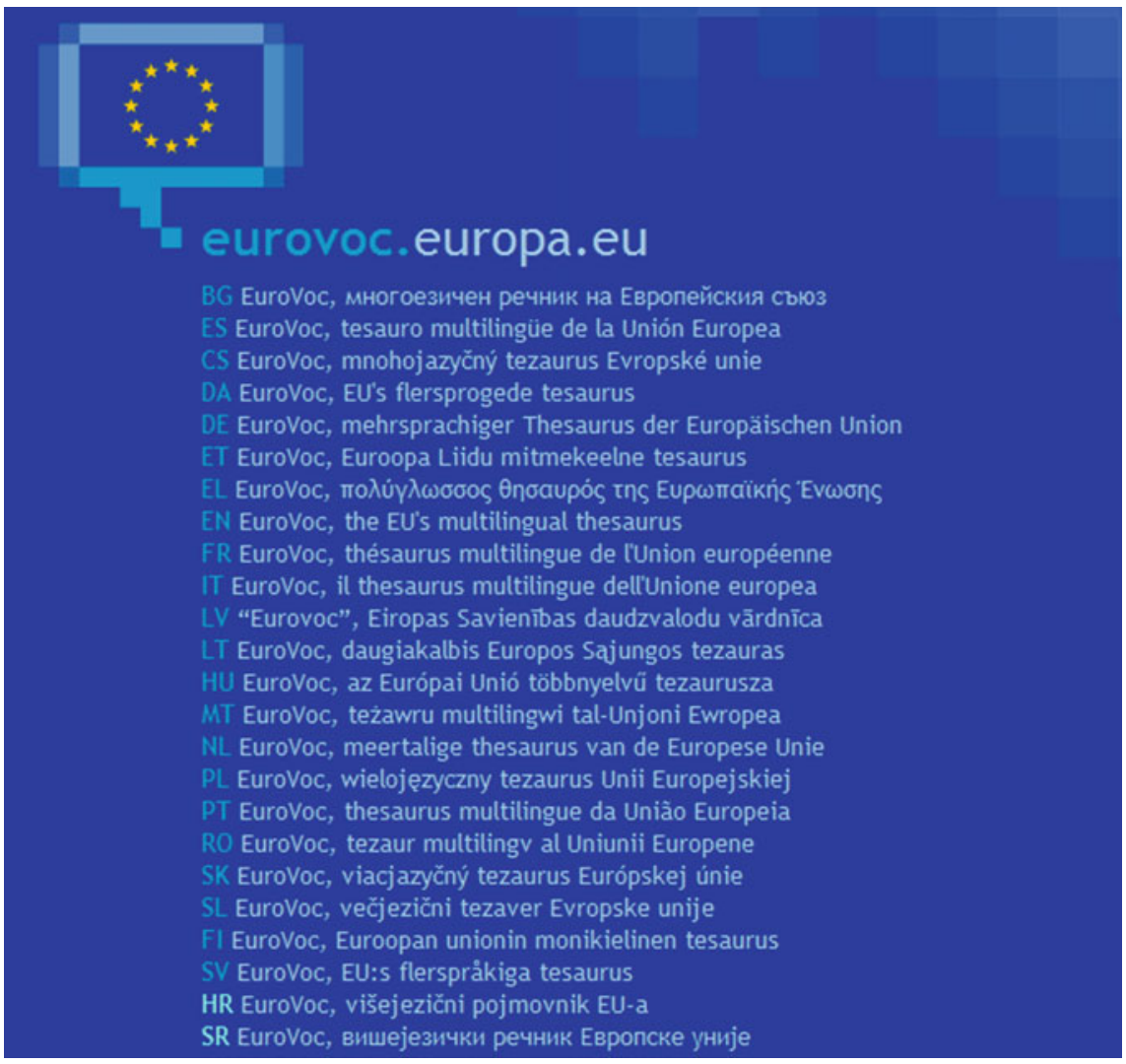

Fig. 4.3 Interface of multilingual thesaurus EuroVoc 


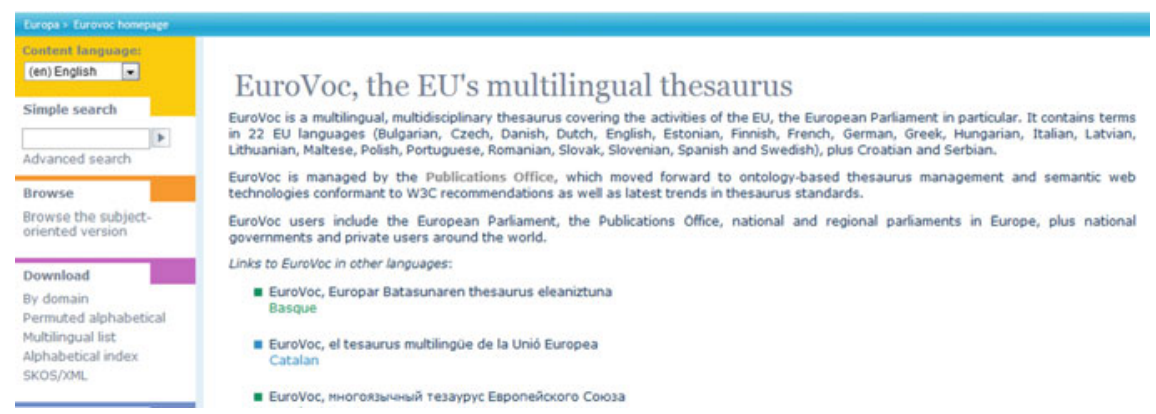

Fig. 4.4 EUROVOC thesaurus, education, communication and communications

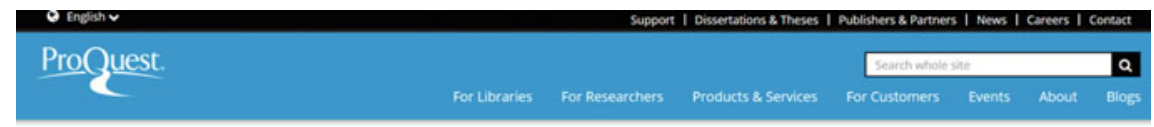

Ready to do some research?
search to access the best journals, databases, and ebook resources from your fovorite libran's collection.

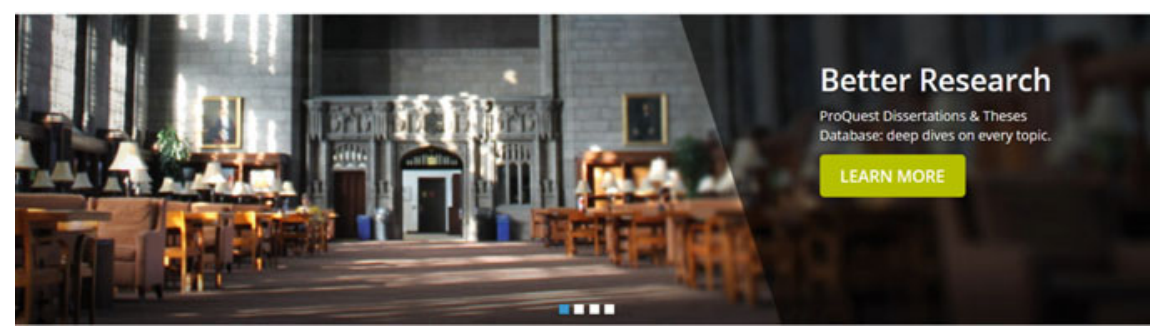

Fig. 4.5 ProQuest provides British Nursing Indexing Thesaurus

\subsection{Boolean Logic Operators}

Boolean search is a method used to combine words and phrases in order to obtain more relevant search results. The principles of Boolean logic will allow you to relate the concepts in sets. Connection terms, known as operators, are used in all types of search, including library catalogues, databases and Internet.

Boolean logic was developed by the Irish mathematician George Bool.

The 3 main Boolean operators are:

AND, OR, NOT. 
< Select another thesaurus

\section{British Nursing Index Thesaurus}

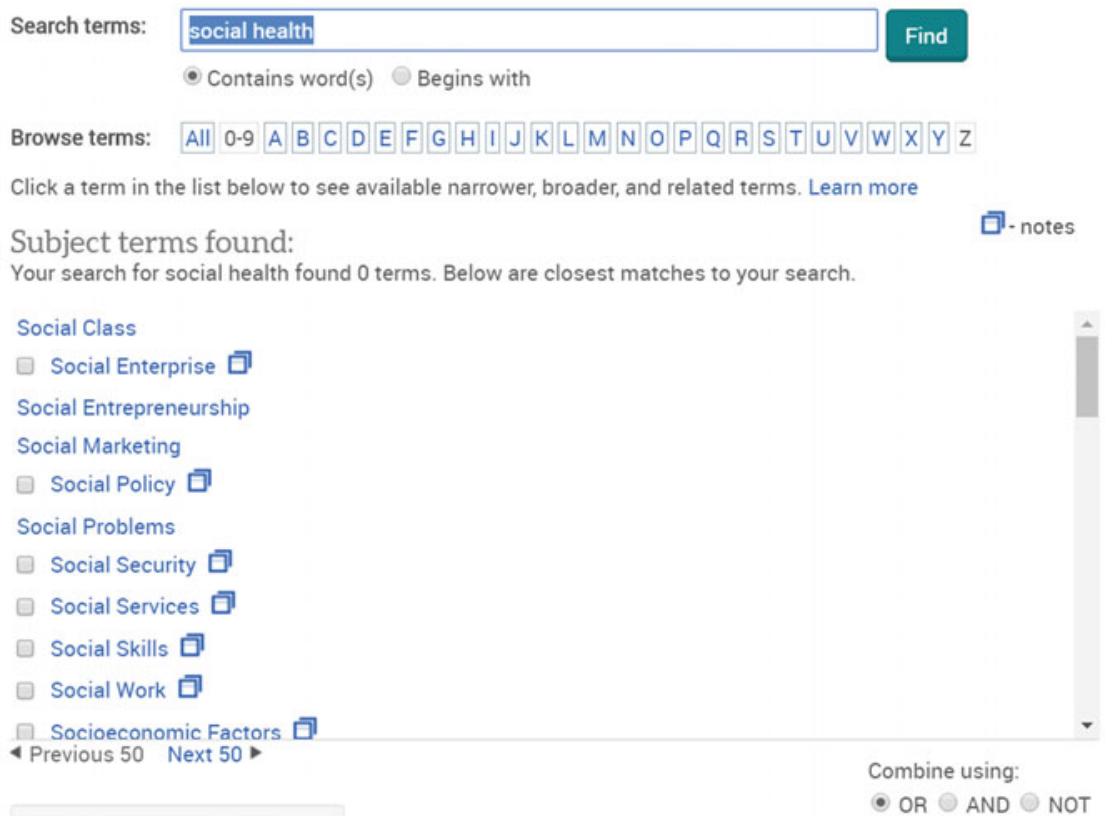

Fig. 4.6 ProQuest provides British Nursing Indexing Tezaurus

Example:

- search word1 AND word2 in order to find documents containing both word1 and word2;

- search word1 NOT word2 in order to find pages containing word1 and not word2;

- search word1 OR word 2 in order to find pages containing the either word1 or word2.

- AND operator directs search

AND operator is used to connect various concepts in order to focus the search.

- OR expands the search area

OR operator is used to connect synonymous terms. It may prove very useful in case a search returns less results than you require. 


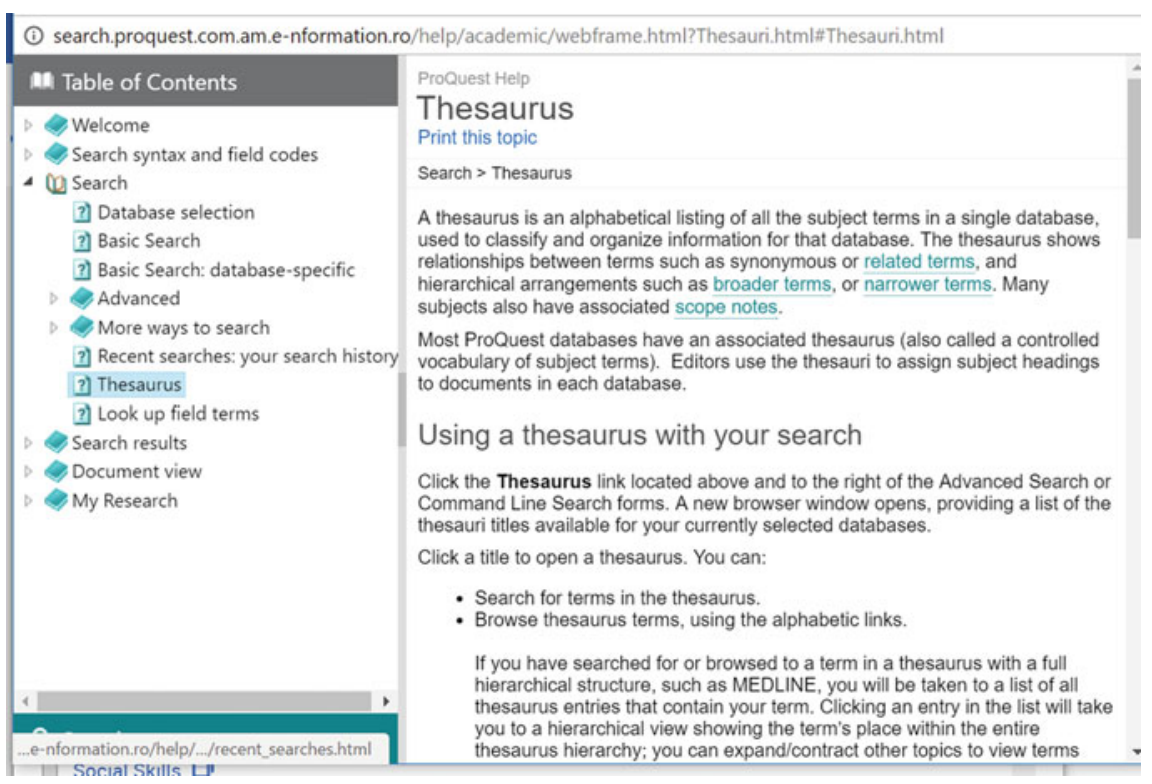

Fig. 4.7 ProQuest provides British Nursing Indexing Tezaurus

- NOT operator narrows the search

Sometimes, when performing a search, a great number of articles upon a certain subject will be returned. The NOT operator may be used to eliminate articles of no relevance.

In case you perform a complex search, the efficiency may be improved by combining searches. Searches are combined by closing individual searches between parentheses and then by connecting these searches with a Boolean operator.

If you retrieve too many results on a given subject then you can use AND to direct your search. The more terms that are connected with AND, the more focused the results. Remove truncation. If you retrieve too many records on an unrelated subject, use NOT to narrow the search. If you get too few records for your topic, use OR to expand your search and to increase the number of references that you are going to find. Use truncation or wildcards in order to seek alternative ways of spelling or choices of your term.

Combining keywords enables finding the most appropriate information resources about a subject. We recommend creating various combinations of keywords using Boolean operators, for example AND-OR-AND NOT. A Boolean machine can help to teach students how these operators work (Fig. 4.8 Boolean machine). 


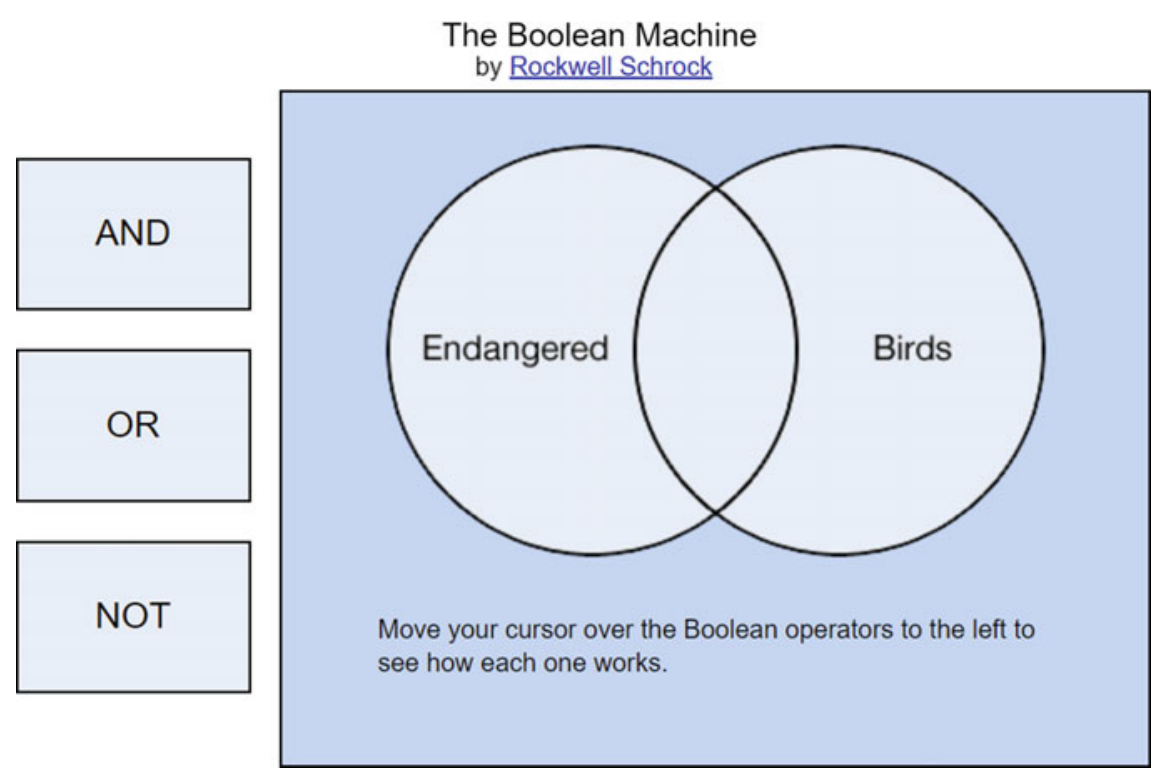

Fig. 4.8 Boolean machine (http://rockwellschrock.com/rbs3k/boolean/)

\subsection{Search of Phrases}

Search of phrases allows you to combine terms so that they are retrieved one next to the other and in the same order; they are indicated putting quotation marks around terms.

For example, "New York Stock Exchange" or "Hilary Rodham Clinton"

\subsection{Truncation}

Truncation may be very useful when you wish to retrieve variants of the same term. In order to truncate a word, keep the root or radical replacing the changing part with a wildcard symbol. The symbol may be *.

Example:

If you wish to search the terms: communication and communicate, the root is "communicat" and the searched truncated term will have the following form: communicat* 


\section{Suggested Teaching \\ Warm-Up/Introduction}

A pre-test

Prepare an envelope with the questions: Who decides what the need for information is? In other words, who decides what information is needed? Who and how can he use the information? What is the cost of knowledge and ignorance?

\section{Variant No. 1}

Divide the participants into three groups. Ask them to choose one leader from each group. He will choose one of the three cards. The trainer will share paper sheets for each participant and explain to the participants that in the first phase they will answer individual questions and query the answers. In the second phase, they will discuss and harmonise the answers. In the third stage, leaders will answer questions with the group's answers and arguments.

\section{Variant No. 2}

Each participant receives one card with all the questions or, as the case may be, the age of the participants, with only one question of those mentioned above, ensuring that all are written on the cards. Also, other questions of greater relevance can be formulated.

Accept any reasonable answer and explain to the students that they will get more information about these topics during the course. Announce the topic to be discussed and the objectives targeted, noting the key terms on a whiteboard or flip chart.

\section{Brainstorming}

Ask students to generate as many ideas as possible for terms referring to "the need of information". Write them on the whiteboard or the flip chart as students express their ideas. At the thought generation stage, no response will be criticised.

Teaching activities

Order of teaching sequences:

1. Learning by discovery for the steps of formulating research questions;

2. The conversation method for understanding conditions that research questions have to meet;

3. Method of Exercise for understanding preliminary research question;

4. Explanation method for understanding research strategy;

5. Mosaic method for information search strategies; and

6. Demonstration and modeling-their formative variances for practising new skills. 


\section{Learning Through Rediscovery for the Steps of Formulating Research Questions}

Problematic situations can be organised in such a way that questions arise in the minds of students without them being formulated by the teacher. A collage of words can be created in a short paragraph. This paragraph will not contain words from which the purpose of communication is deducable, nor will it have unitary writing techniques. It will be vague and nonspecific. Students will be asked to express their opinion on this paragraph.

If independent rediscovery is found to be difficult to implement then directed rediscovery can be used. Thus, the teacher can lead rediscovery through suggestions, questions, and various clues.

The purpose of this teaching sequence is for students to discover the essential questions of defining the need for information:

- What is the purpose of initiating a research?

- What are the appropriate writing techniques?

- What are the most suitable methods to initiate research?

A detailed description of the method can be found in Chap. 10 of this volume.

\section{The Conversation Method for Understanding the Conditions that Research Questions Have to Meet}

These conditions will be written on a flip chart or whiteboard. They can pre-written, prepared and just brought in front of the students. Each condition will be discussed. The benefits of complying with these conditions and the risks assumed when the conditions are not met will be analysed.

Possible questions that can be addressed:

- What do you think are the benefits of meeting these conditions?

- What do you think would happen if they were not observed?

All the answers received will be recorded on the board/flip chart. A detailed description of the method can be found in Chap. 10 of this volume.

\section{The Exercise Method for Understanding Preliminary Research Questions}

Trainers will articulate and explain the three questions and students will be asked to sketch a research topic by answering the three questions. Students have 10-min for the task, after which the research questions that are offered by the students will be discussed. It is recommended only to discuss a maximum of three research 
questions, because the time available will not allow students a profound study of their concerns. If there are more willing, we can ask each participant to focus on the following stages of the lesson, for further clarification, ensuring that in the next lesson or at the end of the lesson, everyone can get feedback for their work.

Uncertainties can be raised, using questions to help the student in his understanding. For example: "The theme that you chose is very interesting. Do you think this theoretical perspective that you have chosen is the most suitable? Could you also find another perspective? What would it be? What conclusions will you reach by studying the methods used by others? What is the purpose of your research? Are there elements of innovation? Can you find some?"

It is advisable to remind students that it is recommended to allocate more time to answer such questions. It can also be a reflection theme for home and can be debated at the next session.

\section{Explanation Method for Understanding the Research Strategy}

The most important ideas from previous tasks can be summarised briefly and make a smooth transition to the task of identifying search strategies.

Very briefly explain to students each method of searching for information and then draw Fig. 3.1, verbalising the steps as they are drawn. If the scheme is pre-prepared, we can save time and spend more time in other tasks. A detailed description of the method can be found in Chap. 10 of this volume.

\section{The Mosaic Method for Information Search Strategies}

The group can be divided into 4 teams. Within these groups each will be asked to pick a number from 1 to 4 , each withholding the chosen number. New groups are formed according to the chosen number, so that all students with the number 1 will sit in a corner of the room, everyone with number 2 in another corner. We will do the same with the number 3 and the number 4 . It is important to tell the students not to forget their original group, and to be attentive about the task, because they will become the spokespersons of the second group, instructing the first group from what it learnt.

Each team will receive a relevant text, prepared in advance. The texts that students will receive are incorporated in the Summary section of this chapter. One group will get the text "Using Key Words", the second "Using a Thesaurus", the third group will receive "Using Boolean Operators", and the final group will receive two smaller sections: "Using Truncation" and "Phrase Search". Students will read the materials and talk to each other in order to understand the fragments. When each group has completed the task they will return to their original group and will share what they have learnt. Eventually, they can build a conceptual map starting from Fig. 3.1. Search Strategies, noting at each point the essential concepts. The teacher will have the task of moderating the discussions, if necessary, as a resource person 
where and when needed. It is important for the teacher to ensure that students understand every strategy. A detailed description of the method can be found in Chap. 10 of this volume.

If the group is smaller and does not allow such a division, we can divide the group into 2 subgroups. One group will have the task of understanding and teaching the first two strategies Using key words and Using thesaurus, and the second group, the other 3 strategies.

\section{Demonstration and Modeling-Their Formative Variations for Practicing New Skills}

Through the demonstration method, described in Chap. 10, the teacher will show students how the search strategies taught work. Likewise, the teacher will make a connection of the research questions, their proper formulation and the need for information. He can use both an inductive approach, as well as a deductive one, according to his preferences and the particularities of the group of trainees.

It would be ideal if the training room was to have enough computers for students to practise what they learned, namely to model the structure proposed by the teacher in order to search required information. During modeling, the role of the teacher is minimised, he becomes a consultant, a mirror reflection of the student. The actions of the trainer will be restrained, having only a supporting role for the student, by formulating some reflexive questions, by encouraging them and monitoring students. At the end of the activity, the teacher will praise student behaviour and will highlight the positive aspects of the activity.

\section{Review}

The teacher together with the students will create a conceptual map, on a flipchart or board, with only the most important issues discussed during the lesson. Since such maps were made throughout the lesson, with more knowledge-building activities, it will have a very short duration. We will call it "Review Knowledge in a Minute". It has the role of imprinting on the minds of trainees the essential concepts, facilitating learning concepts from the lesson.

\section{Suggestions for Solving Your Homework}

\section{Homework:}

Formulate a research topic in your field of study. Focus on a maximum of two research questions. Identify the key terms and start the search process for studies conducted on the subject. 


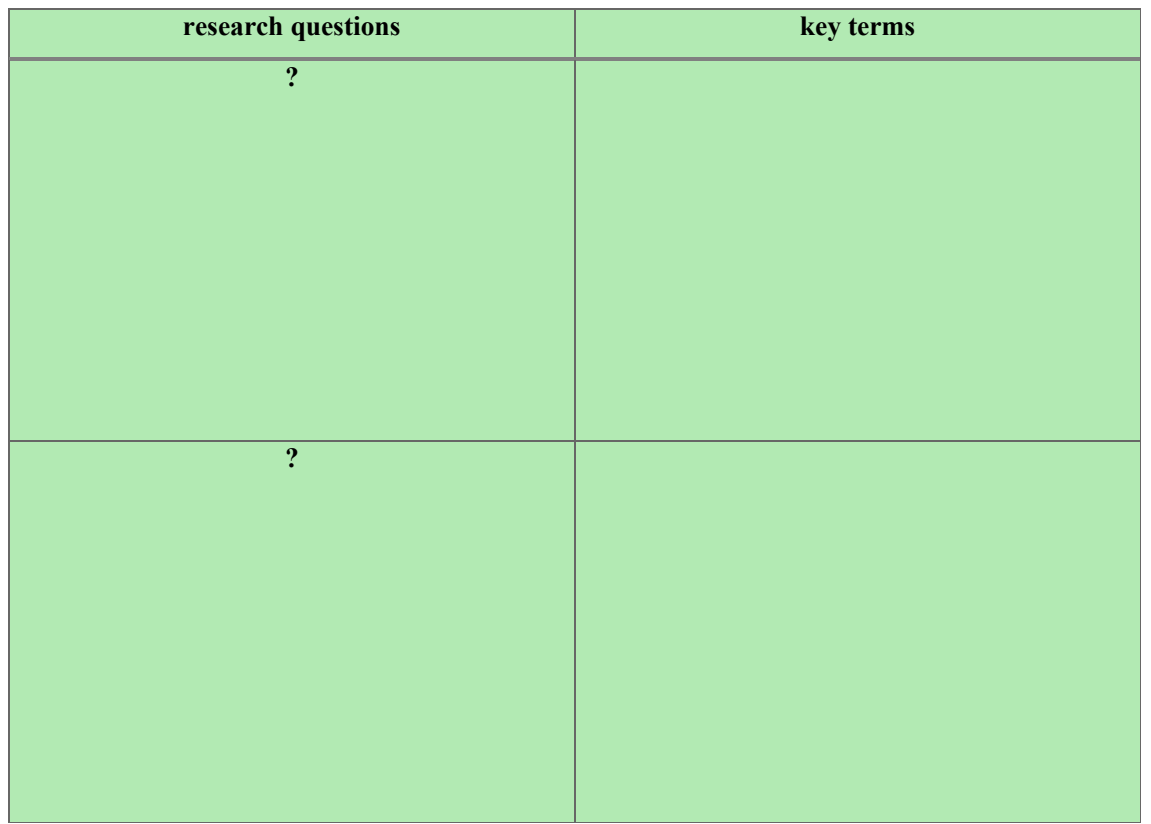

Analyse how many studies you have found. Group them according to certain criteria, which you will specify. Reflect on the results. Write down what new challenges you find.

\begin{tabular}{|l|l|l|l|}
\hline Criterion & Studies & Database & Reflection \\
\hline & & & \\
\hline & & & \\
\hline & & & \\
\hline & & & \\
\hline & & & \\
\hline & & & \\
\hline & & & \\
\hline & & & \\
\hline & & & \\
\hline
\end{tabular}




\section{Applications}

1. Using the Snowball strategy, you can search for information, if you have a keyword or a name. Search for a study relevant to the subject of your research, the names of the authors whom the researcher quotes and make a bibliographic list of those names. Use the same strategy for other papers that you consider relevant.

2. Build a structure to record your searches.

To record searches is as important as search in itself. Organising your search for information by recording searches will relieve you of many inconveniences caused by redundant repetitions.

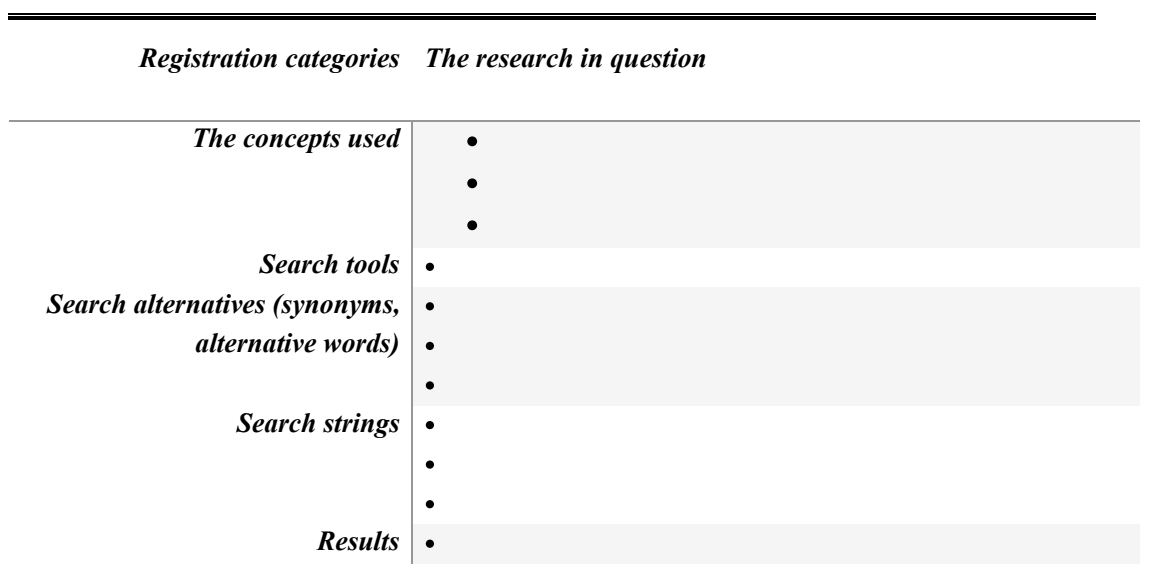

\section{Evaluation}

1. Define the need of information

2. What are the stages for defining a research subject? 
3. What is the condition for formulating the research question?

4. Which research strategies do you know?

\section{Webography}

"Home_Publications Office Of The EU”. (2019). Publications.Europa.Eu. [online] Available at: https://publications.europa.eu/en/web/eu-vocabularies. Accessed February 15, 2019.

"Introduction: What Is Mesh?”. (2019). Nlm.Nih.Gov. [online] Available at: https://www.nlm.nih. gov/bsd/disted/meshtutorial/introduction/. Accessed February 15, 2019.

Proquest.com. (2018). ProQuest | Databases, EBooks and technology for research. [online] Available at: https://www.proquest.com/. Accessed July 13, 2018.

Schrock, R. (2019). Rockwell Schrock's Boolean machine. Rockwellschrock.Com. [online] Available at: 2019. http://rockwellschrock.com/rbs3k/boolean/. Accessed February 15, 2019.

\section{Bibliographic Recommendations}

Emeraldgrouppublishing.com. (2018). Searching for information. [online] Available at: http:// www.emeraldgrouppublishing.com/learning/study_skills/skills/searching.htm. Accessed July $13,2018$.

Searching for information.

\section{How Do I Search for Information?}

University of Greenwich. (2018). How do I search for information? [online] Available at: https:// www.gre.ac.uk/articles/academicskills/How-do-I-search-for-information. Accessed July 13, 2018.

\section{Finding Information for Your Research Paper}

Science Buddies. (2018). Finding information for your research paper. [online] Available at: https://www.sciencebuddies.org/science-fair-projects/science-fair/finding-information-foryour-research-paper\#howtofindinformation. Accessed July 13, 2018. 
Study, H. (2009). How to search for specific information in a particular study. National Center for Biotechnology Information (US). Available at: https://www.ncbi.nlm.nih.gov/books/ NBK99231/ Accessed July 13, 2018.

Open Access This chapter is licensed under the terms of the Creative Commons Attribution 4.0 International License (http://creativecommons.org/licenses/by/4.0/), which permits use, sharing, adaptation, distribution and reproduction in any medium or format, as long as you give appropriate credit to the original author(s) and the source, provide a link to the Creative Commons license and indicate if changes were made.

The images or other third party material in this chapter are included in the chapter's Creative Commons license, unless indicated otherwise in a credit line to the material. If material is not included in the chapter's Creative Commons license and your intended use is not permitted by statutory regulation or exceeds the permitted use, you will need to obtain permission directly from the copyright holder.

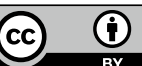

